\title{
Environmental and occupational respiratory diseases - 1060. Clinical responses to methylprednisolone pulse therapy in children with severe refractory mycoplasma pneumoniae pneumonia
}

\author{
Jae Ho Lee ${ }^{1^{*}}$, Sun Young You' ${ }^{1}$ Eun Ae Yang ${ }^{1}$, You Sook Youn ${ }^{2}$, Hong Ryang Gil ${ }^{1}$ \\ From 2nd WAO International Scientific Conference (WISC 2012) \\ Hyderabad, India. 6-9 December 2012
}

\section{Background}

Mycoplasma pneumoniae (M. pneumoniae) pneumonia is one of the most common causes of community acquired pneumonia in children. The clinical course is usually self limited and benign. But rarely severe pneumonia could be complicated despite appropriate antibiotic therapy. We determine the impact of methylprednisolone pulse therapy on the severe refractory $M$. pneumoniae pneumonia in children.

\section{Methods}

We evaluated the clinical effects of steroid pulse therapy retrospectively in 12 children with severe refractory M. pneumoniae pneumonia, diagnosed serologically. All of the patients, who showed the respiratory distress, high fever and initial lobar pneumonic consolidation with pleural effusion radiologically, and deteriorated despite of antibiotic therapy were treated with intravenous methylprednisolone pulse therapy in addition to antibiotics.

\section{Results}

The average febrile period prior to admission was $4.9 \pm 1.7$ days and that was $3.7 \pm 1.6$ days after using antibiotics. We initiated methylprednisolone pulse therapy at a dose of $30 \mathrm{mg} / \mathrm{kg}$ on the day $5.4 \pm 2.5$ of admission. After pulse therapy, the clinical symptoms and signs

'Pediatrics, Chungnam National University School of Medicine, Dae Jeon, South Korea

Full list of author information is available at the end of the article were improved in all patients without adverse events of steroid therapy. In particular, the high fever was subsided within 0-2 hours after initiation of steroid pulse therapy. The abnormal radiologic findings were resolved on the days $2.6 \pm 1.3$ and the high levels of C-reactive protein $(6.7 \pm 5.9 \mathrm{mg} / \mathrm{dl}$ on admission) was decreased to $1.3 \pm 1.7 \mathrm{mg} / \mathrm{dl}$ on the days $3.0 \pm 1.1$ of steroid therapy.

\section{Conclusions}

This study showed an impact of 3-day methylprednisolone pulse therapy on severe refractory $M$. pneumoniae pneumonia in children despite appropriate antibiotic therapy. The steroid pulse therapy is apparently an efficacious and well-tolerated treatment for severe refractory M. pneumoniae pneumonia.

\section{Author details}

'Pediatrics, Chungnam National University School of Medicine, Dae Jeon, South Korea. ${ }^{2}$ Pediatrics, St Mary's Hospital, The Catholic University of Korea, Daejon, Korea.

Published: 23 April 2013

\section{doi:10.1186/1939-4551-6-S1-P58}

Cite this article as: Lee et al:: Environmental and occupational respiratory diseases -1060 . Clinical responses to methylprednisolone pulse therapy in children with severe refractory mycoplasma pneumoniae pneumonia. World Allergy Organization Journal 2013 6(Suppl 1):P58.

(c) 2013 Lee et al; licensee BioMed Central Ltd. This is an Open Access article distributed under the terms of the Creative Commons 